\title{
Desafios para uma abordagem CTS dos artefatos das biotecnociências
}

\section{Challenges for a STS approach to biotechnology artifacts}

\author{
Cláudia Santos Turco \\ Programa de Pós-Graduação em História das Ciências e das Técnicas e Epistemologia \\ (HCTE), Universidade Federal do Rio de Janeiro (UFRJ). \\ claudia.turco@hcte.ufrj.br \\ orcid.org/0000-0002-4792-8282
}

\section{Eduardo Nazareth Paiva}

Programa de Pós-Graduação em História das Ciências e das Técnicas e Epistemologia (HCTE), Universidade Federal do Rio de Janeiro (UFRJ). edu@hcte.ufrj.br orcid.org/0000-0003-0191-4501

Resumo. Este texto levanta as dimensões de análise que surgem ao pesquisar novas biotecnologias em um Programa de Pós-Graduação em História das Ciências e das Técnicas e Epistemologia. O desafio é seguir uma nova biotecnologia que está sendo implementada com o objetivo de controlar algumas arboviroses, como dengue, zika e chikungunya. $\mathrm{O}$ olhar proposto relaciona-se, por um lado, com a recusa em analisar uma tecnologia como algo separado de seu contexto de criação e utilização e, por outro, com a ideia de que os artefatos das biotecnociências se criam e recriam constantemente num entrelace de relações socionaturais e que estes têm sua própria linha de atuação, sua agência, nem sempre de acordo com as expectativas humanas.

Palavras-chave: Biotecnociência. CTS. Aedes aegypti. Wolbachia.

Abstract. This text discusses the dimensions of analysis that arise when researching new biotechnologies in a Postgraduate Program in the History of Sciences and Techniques and Epistemology. The challenge is to understand a new biotechnology that is being implemented in order to control some arboviruses, such as dengue, zika and chikungunya. The proposed point of view is related, on one hand, to the refusal to analyze a technology as something separate from its context of creation and use and, on the other hand, to the idea that biotechnoscience artifacts are 
constantly created and recreated in a intertwining of socionatural relations and that they have their own line of action, their agency, not always meeting human expectations.

Keywords: Biotechnoscience, STS, Aedes aegypti, Wolbachia.

Recebido: 01/10/2018 Aceito: 27/10/2018 Publicado: 05/11/2018

\section{Mosquitos infectados}

O presente trabalho apresenta os desafios enfrentados para historicizar a implantação de uma nova biotecnologia utilizada para o controle de arboviroses como dengue, zika e chikungunya: os mosquitos Aedes aegypti infectados pela bactéria Wolbachia.

Os mosquitos infectados com Wolbachia são produto do projeto World Mosquito Project, iniciado na Austrália e atualmente ativo em 10 diferentes países, e que tem como objetivo contribuir para o controle da transmissão da dengue e de outras arboviroses através da utilização de mosquitos Aedes aegypti infectados com a bactéria Wolbachia. O projeto iniciou atividades no Brasil em 2012 e a primeira soltura de mosquitos infectados no ambiente ocorreu em 2014, no bairro Ilha do Governador, no Rio de Janeiro.

A Wolbachia é uma bactéria encontrada em diversos insetos, mas que foi introduzida no Aedes aegypti pelo homem. Esta infecção impede que o vírus da dengue, assim como da Zika, da Chikungunya, da febre amarela, entre outros, se desenvolva no mosquito e, como consequência, impede a sua transmissão para humanos. As fêmeas infectadas são liberadas no ambiente e sua prole ou é infectada pela Wolbachia ou seus ovos não eclodem. Assim, esta tecnologia não objetiva a supressão da população de Aedes aegypti, mas a substituição da população de mosquitos selvagens por mosquitos infectados com Wolbachia. Os mecanismos através dos quais esta interferência se dá ainda não estão claros e algumas hipóteses estão sendo avaliadas, como aumento da resposta imune dos hospedeiros ou competição direta por recursos com outros patógenos.

Um ponto de crucial importância para o sucesso desta estratégia é a manutenção da disseminação da bactéria na população de mosquitos selvagens ao longo do tempo e independente da continuidade das solturas. Pelos estudos realizados em laboratório e em gaiolas de mosquitos, as fêmeas de mosquitos transinfectados têm a capacidade de transmitir a bactéria para sua prole em alta frequência de forma que esta se espalha pela população de mosquitos selvagens. Já os machos não transmitem a Wolbachia para sua prole, no entanto, as fêmeas selvagens não infectadas ao cruzarem com machos infectados não produzem descendentes (ITURBE-ORMAETXE, WALKER e O'NEILL, 2011).

Neste sentido, ao contrário dos diversos mecanismos de controle da população de mosquitos atualmente utilizados, esta tecnologia é uma proposta de mudança consciente e ousada, pois busca infectar toda a população de uma espécie animal, assumindo que humanos, mosquitos e vírus continuarão a conviver. Além disso, toda a proposta baseia 
sua sustentabilidade na agência dos mosquitos e das bactérias, na sua capacidade de manutenção independente do homem, e em sua irreversibilidade.

Este trabalho tem como foco discutir as diferentes dimensões de análise que se colocam no momento em que pensamos os novos artefatos da biotecnociência, como os mosquitos infectados com Wolbachia.

\section{Por que falar sobre isso?}

Sugere-se a identificação do problema e contornos científicos/acadêmicos pré-existentes à sua pesquisa. Idealmente o tópico Introdução deve desenvolver-se de modo a revelar a lacuna a ser respondida, total ou parcialmente, pela pesquisa aqui apresentada, bem como as apostas do autor neste ou naquele caminho através da associação de pesquisas realizadas em diferentes campos do conhecimento, e que estão sendo relacionadas na linha investigativa do presente artigo.

Mas por que pesquisar biotecnologias? Primeiro, é necessário definir o conceito adotado de biotecnologia. Aqui propomos adotar a definição de biotecnologia como "atividade baseada em conhecimentos multidisciplinares, que utiliza agentes biológicos para fazer produtos úteis ou resolver problemas” (MALAJOVICH, 2016, p. 2). Já a relação saúdebiotecnologia pode ser definida como "qualquer exploração tecnológica da biodiversidade para resolver problemas de saúde do homem" (GARCIA, 1995). Estas definições são amplas o suficiente para abranger diferentes campos e formas de atuação e, na saúde, incluem qualquer utilização da biodiversidade, seja com técnicas estritamente da genética, mas também de outras áreas da biologia, como da biologia celular e molecular, bacteriologia, botânica, fisiologia de plantas, etnobotânica, entre outras.

Os humanos manipulam a natureza de diversas formas há muito tempo, como na domesticação de animais, no cultivo de alimentos e na utilização de plantas como medicamentos. No entanto, desde a segunda metade do século XIX, mudanças na escala e na forma desta manipulação aparecem. Em primeiro lugar, o desenvolvimento da microbiologia, da imunologia, da bioquímica e da genética como novos campos de pesquisa abrem novas possibilidades de aplicação destes conhecimentos. Ainda, como nossa própria definição coloca, as biotecnologias modernas passam, cada vez mais, a serem utilizadas para "fazer produtos úteis ou resolver problemas", deixando de ser práticas preponderantemente laboratoriais para entrar nas linhas de produção e em nossas vidas. Especificamente no campo das práticas de saúde coletiva, a utilização de artefatos biotecnológicos não é tão recente. A manipulação de seres vivos no ambiente e nos corpos individuais - seja sua disseminação, seu extermínio ou sua recriação - tem sido utilizada em diversas iniciativas, como nas campanhas de imunização e de extermínio de vetores. Essas práticas criam, por tradução ou translação, seres híbridos de natureza e sociedade completamente novos (LATOUR, 1994), como vírus atenuados, insetos transgênicos entre outros. 
A novidade, neste momento histórico, é a escala em que essas biotecnologias invadiram a vida, tanto no que se refere a corpos humanos e não-humanos quanto ao ambiente. Alguns autores, como Jonas (2006), colocam que as biotecnociências modernas ampliaram o alcance de nossas ações, transformando em metas o que antes era apenas utopia; em projetos realizáveis o que antes eram jogos experimentais. Não há como refletir sobre processos sociais e sobre processos naturais sem que se pense no caráter cultural da natureza ou, como Ianni (2011) diz, sem fazer uma história humana da natureza. Este fim da distinção entre história humana e história natural é também trazido por Chakrabarty (2009). Este autor coloca que o que chamamos de natureza ou ambiente apareceu para a história com papel central ainda na primeira metade do século passado, no trabalho de Fernand Braudel sobre o Mediterrâneo. Neste caso, o ambiente aparece como ator que molda as ações humanas, num ritmo lento que para a percepção humana parece estático. No entanto, esse ambiente aparentemente parado pode ganhar velocidade em sua relação com os humanos. Outro ponto levantado por Chakrabarty (2009) é que, além de agência biológica que os humanos sempre tiveram, agora temos uma agência geológica.

"Não houve nenhum momento na história humana no qual humanos não fossem agentes biológicos. Mas apenas histórica e coletivamente pudemos nos tornar agentes geológicos, isto é, quando tivemos números e inventamos tecnologias que estão em uma escala grande o suficiente para ter impacto no próprio planeta" (CHAKRABARTY, 2009, p. 206-207).

Aparece, então, uma nova dimensão de análise. Não apenas a história humana é inseparável da história natural; não apenas o ambiente tem papel intrínseco na história humana; mas os humanos aparecem como atores ativos na história natural. No caso dos artefatos biotecnológicos criados e disseminados, estes não apenas afetam um ambiente local ou corpos individuais, mas podem ter impactos globais os quais nem sempre são perceptíveis em um primeiro momento, mas algumas vezes são desenhados com este objetivo.

Ao analisar biotecnologias, buscaremos lançar nosso olhar para a sua intromissão, ou seja, para a característica ubíqua destas tecnologias, que se fazem presentes no ambiente e em nossos corpos. Mas buscaremos ainda olhar para estes híbridos biotecnológicos como agentes de transformações nem sempre esperadas pelos humanos. Como dizem Callon e Rabeharisoa (2017), se compararmos os artefatos das biotecnociências com artefatos produzidos por outras disciplinas, como a física ou a química, teremos comportamentos, agências, bem diferentes.

"Um driver de CD-ROM atua (quase) da mesma maneira no laboratório como em uma residência particular. Com a química, pelo contrário, as coisas começam a se tornar mais complicadas. As substâncias químicas que compartilham nossas vidas e, algumas vezes, as facilitam, estão 
constantemente agindo, reagindo, combinando e desencadeando reações em cadeia (a terminologia química atesta essa atividade). Resumindo, são menos previsíveis, mas difíceis de enquadrar e a fonte de transbordamento repentino ou mesmo explosão. Finalmente, com a biologia, a biotecnologia e especialmente a genômica, a diferença é ainda maior. the difference is even greater. As entidades não são simplesmente reativas; elas vivem as suas vidas, mesmo depois de saírem do laboratório. O que acontece dentro do laboratório não permite prever inteiramente o que é provável acontecer do lado de fora. Para um objeto das ciências da vida, existir é transbordar" (CALLON e RABEHARISOA, 2017, p. 251).

Esta é mais uma dimensão de análise: as previsões de comportamento e as probabilidades de risco para os humanos e para o ambiente trazidas por estes artefatos. A distância entre o comportamento de seres vivos no ambiente e em laboratórios é enorme. Isto significa que soltar artefatos da biotecnociência produzidos em laboratórios no ambiente sempre traz um grau de imprevisibilidade, incerteza e risco.

Mas o que queremos dizer com risco e, em especial, com risco em saúde? Risco é uma forma presente de descrever o futuro e gestão do risco assume, por um lado, que é possível evitar ou minimizar o risco prevendo e controlando as consequências das ações e decisões humanas e, por outro, assume que é possível decidir qual é o futuro desejável (CASTIEL, 2003). A preparação para o risco, em nossa sociedade, portanto, não tende a evitar o perigo, e envolve o uso da biotecnociência para criar, modificar ou exterminar o que usualmente era denominado de natureza.

Estes híbridos de natureza-sociedade, por sua imprevisibilidade no tempo e no espaço, fazem com que os riscos tenham uma dimensão potencialmente global, mesmo que sua manifestação material seja local, situada. No campo da Saúde Pública, estes híbridos se encontram com políticas de ampla abrangência - nacionais e muitas vezes globais. Os artefatos da saúde pública ganham materialidade nos laboratórios, mas logo passam a circular em outros domínios, como serviços de vigilância, postos de saúde, hospitais, fábricas de medicamentos, gabinetes de políticos e gestores públicos, tribunais, organizações de pacientes entre outros. Nessas transposições, nestas arenas transepistêmicas (KNORR-CETINA, 1982), os artefatos são traduzidos e muitas vezes traídos, e seus comportamentos tornam-se imprevisíveis.

A Saúde Pública/Coletiva é, no atual contexto de desenvolvimento técnico-científico, uma importante esfera social de produção de híbridos e riscos. A Saúde Pública catalisa híbridos e riscos (IANNI, 2011, p. 839). 
Mas quem decide o que é risco e que riscos devemos assumir? Quem decide o grau de alteração sociobiológica aceitável? Até o momento, olhamos para a dimensão do risco que é construída em laboratórios e transportada para outros ambientes. Mas estes riscos são também uma construção cultural, que se baseia na percepção de diversos atores e que é moldada por vários canais (IANNI, 2011). Portanto, como (GARCIA, 1995) coloca, as estratégias e iniciativas que envolvem artefatos da biotecnociência devem passar por debate público. O debate público é necessário pois é necessário lembrar que a legislação, em especial a brasileira, não inclui em seu arcabouço alguns desses artefatos, como, por exemplo, a lacuna referente a animais modificados, geneticamente ou não. Nestes casos, alguns artefatos das biotecnociências, para serem transladados dos laboratórios para o mundo, precisam ter alinhavado, construído, seu caminho por diversas instituições, como comitês de ética e órgãos de licenciamento e fiscalização.

Uma outra dimensão refere-se às controvérsias relativas a epidemias e a seus meios de controle, não apenas no âmbito da tecnociência, mas de forma mais ampla. A epidemias, seus efeitos e suas estratégias de controle são bem reconhecidos pela experiência humana, trazendo consigo a percepção do risco e a insegurança e caracterizam-se pela dramaticidade e pelo poder de mobilização de indivíduos e comunidades. Há constantes controvérsias relativas a todas as técnicas de controle do Aedes Aegypti, em especial as de base química (inseticidas e larvicidas) e as de base biotecnológica. Por outro lado, os efeitos das epidemias de dengue e, mais recentemente, de Zika e chikungunya também tomam seu espaço no debate público. Esta situação, então, tende a facilitar a aceitação de novas tecnologias, cujos riscos são de difícil percepção em nosso cotidiano.

\section{Reflexões finais}

Logo no primeiro capítulo do livro The Mushroom at the end of the World: on the possibility of life in capitalist ruins (TSING, 2015), a autora entra em uma de suas florestas e traz palavras que a auto-definem como como perdida, desorientada, de mãos vazias e sem ter trazido nada. O lugar é descrito como uma floresta que parecia pouco promissora e onde nada crescia. Ao andar aos tropeços, a autora coloca que encontrou uma estrada, mas não sabia que caminho seguir, até que encontrou alguém que a levou a seus cogumelos. Nem assim Tsing se tranquilizou. Esses encontros foram para ela perturbadores e surpreendentes e ela coloca que escreveu seu livro como uma tentativa de descobrir os caminhos desse labirinto.

Tsing fala do conceito de diversidade contaminada, e traz aí a possibilidade de vida a partir de ruínas, de ambientes desgastados, modificados. Esta não seria uma vida como em épocas anteriores, mas sim uma nova vida, com uma combinação nova de elementos que se relacionam em novos e inesperados entrelaçamentos.

Podemos pensar o ambiente urbano como um local que reúne muitos elementos heterogêneos e onde não é possível saber ao certo como estes irão se combinar e quais serão os acontecimentos. O homem não está no controle. 
Aqui buscou-se refletir sobre os novos artefatos da biotecnociência que se conjugam com políticas públicas de saúde e produzem dimensões de análise que devem ser exploradas. No caso específico dos mosquitos Aedes aegypti infectados com a bactéria Wolbachia, estes são produtos da biotecnociência que fogem dos tradicionais, e muitas vezes controversos, métodos de controle das arboviroses, que, em geral, visam a supressão da população de mosquitos, É uma biotecnologia que assume que o convívio de humanos, mosquitos e vírus será continuado e que se apoia explicitamente na agência conjunta de humanos e não humanos; em sua capacidade de replicação independente da ação humana; e em sua irreversibilidade.

\section{Financiamento}

O presente trabalho foi realizado com apoio da Coordenação de Aperfeiçoamento de Pessoal de Nível Superior - Brasil (CAPES) - Código de Financiamento 001.

\section{Referências}

CALLON, M.; RABEHARISOA,. The Growing Engagement of Emergent Concerned Groups in Political and Economic Life: Lessons from the French Association of Neuromuscular Disease Patients. Science, Technology \& Human Values, 2, 12 novembro 2017. 230-261. Disponivel em: <https://journals.sagepub.com/doi/10.1177/0162243907311264\#>. Acesso em: 3 outubro 2018.

CASTIEL, L. D. Insegurança, ética e comunicação em saúde pública. Revista de Saúde Pública, 2, 2003. 161-167. Disponivel em: <http://www.scielo.br/pdf/rsp/v37n2/15281.pdf>. Acesso em: 03 maio 2018.

CHAKRABARTY, D. The Climate of History: Four Theses. Critical Inquiry, 35, n. 2, 2009. Disponivel em: <https://www.jstor.org/stable/10.1086/596640>. Acesso em: 10 agosto 2018.

GARCIA, E. S. Biodiversidade, Biotecnologia e Saúde. Cadernos de Saúde Pública, Rio de Janiro, 3, julho/setembro 1995. 491-494. Disponivel em: <http://www.scielo.br/pdf/csp/v11n3/v11n3a12.pdf>. Acesso em: 03 outubro 2018.

IANNI, Á. M. Z. Saúde Pública e Colonização da Naturez. Physis Revista de Saúde Coletiva, Rio de Janeiro, 4, 23 junho 2009. 1029-1050. Disponivel em: <http://www.scielo.br/pdf/physis/v19n4/v19n4a07.pdf>. Acesso em: 19 julho 2018.

IANNI, A. M. Z. Desafios para um novo pacto sanitário: biotecnologia e risco. Ciência \& Saúde Coletiva, Rio de Janeiro, 1, 2011. 837-846. Disponivel em: $<$ http://www.scielo.br/scielo.php?script=sci_arttext\&pid=S1413-

$81232011000700015 \& \operatorname{lng}=$ pt\&nrm=iso $>$. Acesso em: 03 outubro 2018. 
ITURBE-ORMAETXE, I.; WALKER, T.; O'NEILL, S. L. Wolbachia and the Biological Control of Mosquito-Borne Disease. EMBO Reports, 6, 06 maio 2011. 508-518. Disponivel em: <http://dx.doi.org/10.1038/embor.2011.84>. Acesso em: 30 setembro 2018.

JONAS, H. O princípio responsabilidade: ensaio de uma ética para a civilização tecnológica. Rio de Janeiro: Contraponto, 2006.

KNORR-CETINA, K. D. Scientific Communities or Transepistemic Arenas of Research? A Critique of Quasi-Economic Models of Science. Social Studies of Science, 12, n. 1, 01 fevereiro 1982. 101-130. Disponivel em: <https://journals.sagepub.com/doi/10.1177/030631282012001005>. Acesso em: 3 outubro 2018.

LATOUR, B. Jamais fomos modernos: ensaio de antropologia simétrica. Rio de Janiro: Ed.34, 1994.

MALAJOVICH, M. A. M. D. Biotecnologia. 2. ed. Rio de Janeiro: BTeduc, 2016. 301 p. ISBN: 978-85-921077-0-3.

TSING, A. L. The mushroom at the end of the world: On the possibility of life in capitalist ruins. [S.1.]: Princeton University Press, 2015. 414 p. ISBN 978-0-691-162751. 